\title{
Estudo da percepção ética dos estudantes de graduação diante de dilemas concernentes a atividade turística
}

\author{
Study of ethical perception of undergraduate students on dilemmas \\ concerning tourism
}

\section{Estudio de la percepción ética de los estudiantes universitarios en el ámbito del turismo dilemas}

\section{Taís Alexandre Antunes Paes ${ }^{1}$ Denio Santos Azevedo}

Resumo: O presente estudo teve como objetivo analisar a percepção ética dos estudantes diante de dilemas éticos de cunho social, econômico e ambiental comuns a atividade turística. A prática do turismo constantemente apresenta dilemas éticos em que os seus agentes sociais necessitam tomar decisões. Dependendo da forma como estas são tomadas, os efeitos, de tais ações, podem gerar benefícios ou malefícios para a sociedade devido às trocas constantes que ocorrem entre estes agentes sociais quando há a aquisição de serviços e produtos turísticos. É devido a tais aspectos que se faz proeminente analisar a percepção ética dos estudantes, uma vez que os mesmos serão futuros tomadores de decisões ou prestadores de serviços turísticos. Desta maneira, foram entrevistados 103 graduandos do curso de turismo de uma universidade pública do nordeste brasileiro considerando uma amostragem não-probabilística por acessibilidade e conveniência. Para tal análise foi desenvolvida uma escala com cenários de cunho social, econômico e ambiental. Os itens basearam-se nas seis questões morais pertencentes ao modelo integrativo de Jones (1991) que em conjunto formam a intensidade moral: magnitude das consequências, consenso social, probabilidade de efeito, imediatismo temporal, proximidade e concentração do efeito. Entre os resultados está uma maior percepção ética para o dilema de cunho ambiental e uma tendência de ação antiética para o dilema de cunho econômico.

Palavras-chave: Atividade Turística. Percepção Ética. Graduação em Turismo

Abstract: This study aimed to analyze the ethical perception of students on ethical dilemmas of social, economic and environmental common tourist activity. The practice of tourism constantly presents ethical dilemmas in their social actors need to make decisions. Depending on how decisions are taken the effects of such actions, can generate benefits or harms to society due to the constant changes that occur between these social agents when there is the purchase of services and tourism products. It is due to such aspects that makes prominent analyze the ethical perception of the students, since they will be future decision makers and tourism service providers. In this way, we interviewed 103 undergraduate students of tourism course at a public

1 Mestre em Gestão Organizacional pelo PPGA/UFPB. Professora efetiva do Curso de Turismo da Universidade Federal de Sergipe (UFS), São Cristóvão, Sergipe, Brasil. E-mail: taletunes@yahoo.com.br.

2 Doutor em Sociologia. Professor da Universidade Federal de Sergipe (UFS), São Cristóvão, Sergipe, Brasil. Email: denio azevedo@yahoo.com.br 
university in northeastern Brazil considering a non-probability sampling for accessibility and convenience. For this analysis was developed with a range of social, economic and environmental nature scenarios. The items were based on six moral issues pertaining to the integrative model Jones (1991) which together form the moral intensity: the magnitude of the impact, social consensus effect of probability, time immediacy, concentration and proximity effect. Among the results is greater ethical awareness for environment-related dilemma and an unethical action tendency for economic die dilemma.

Keywords: Tourist activity. Ethics perception. Degree in Tourism

Resumen: Este estudio tuvo como objetivo analizar la percepción ética de los estudiantes sobre los dilemas éticos de la actividad turística común social, económico y ambiental. La práctica del turismo presenta constantemente dilemas éticos en sus actores sociales necesitan para tomar decisiones. Dependiendo de cómo se toman las decisiones los efectos de este tipo de acciones, puede generar beneficios o daños a la sociedad debido a los constantes cambios que se producen entre estos agentes sociales cuando no es la compra de servicios y productos turísticos. Es debido a estos aspectos que hace prominente analizar la percepción ética de los estudiantes, ya que serán futuros tomadores de decisiones y los proveedores de servicios turísticos. De esta manera, hemos entrevistado a 103 estudiantes de pregrado de Turismo curso en una universidad pública en el noreste de Brasil considerando un muestreo no probabilístico para la accesibilidad y comodidad. Para este análisis se desarrolló con una serie de escenarios sociales, económicos y ambientales. Los artículos se basan en seis cuestiones morales relacionadas con el modelo integrador Jones (1991), que en conjunto forman la intensidad moral: la magnitud del impacto, efecto consenso social de la probabilidad, de inmediatez tiempo, concentración y efecto de proximidad. Entre los resultados es mayor la conciencia ética para dilema relativos al medio ambiente y una tendencia a la acción poco ética para dilema matriz económica.

Palabras clave: La actividad turística. Ética percepción. Grado en Turismo

\section{INTRODUÇÃO}

A atividade turística em diversas localidades é responsável pela geração de renda permitindo, em muitos casos, o desenvolvimento econômico, social e ambiental. Em tais relações o componente da troca, principal elemento da atividade de marketing, se faz presente. $\mathrm{Na}$ atividade turística tal preceito ocorre em muitas relações, no momento, por exemplo, em que um turista ou visitante frequenta um restaurante onde o mesmo recebe a prestação de um serviço e paga por este. Esta também ocorre quando os turistas visitam um museu que pagam pela sua entrada e recebem o conhecimento de práticas culturais, saberes e fazeres e bens culturais diferentes dos seus. Ou seja, independente da maneira como a atividade turística ocorre o aspecto da troca é proeminente.

Assim, nas relações de troca a necessidade de condutas éticas, por parte dos prestadores de serviços turísticos, é importante, visto que, são agentes sociais cujas atitudes e ações afetam a sociedade de uma maneira geral. É devido a tais aspectos que há a necessidade de se analisar as condutas éticas dos futuros agentes sociais no intuito de conduzi-los de forma a apresentarem posturas mais éticas diante dos dilemas comuns à atividade turística. Neste sentido, esta pesquisa busca analisar a percepção ética dos estudantes diante de dilemas éticos de cunho social, econômico e ambiental, comuns a atividade turística.

Para atingir este objetivo foi desenvolvida uma escala constituída de cenários envolvendo dilemas de cunho social, econômico e ambiental. Para a elaboração dos itens utilizouse o modelo da intensidade moral proposta por Jones (1991) que indica que o componente 
moral é formado por seis variáveis principais: magnitude das consequências, consenso social, probabilidade de efeito, imediatismo temporal, proximidade e concentração do efeito. $\mathrm{Na}$ opinião de Jones, evidências prévias sugerem que os seres humanos reagem ou respondem de diferentes formas diante de questões morais em que precisam tomar decisões.

Para cada um dos cenários desenvolvidos, os 103 (cento e três) estudantes entrevistados tiveram de se posicionar em relação, aos itens relacionados às seis características da intensidade moral através da escala phrase completion proposta por Hodge e Gillspie (2007). A amostra dos estudantes foi composta por graduandos do curso de turismo de uma universidade pública do nordeste brasileiro considerando uma amostragem não probabilística por acessibilidade e conveniência.

\section{CARACTERÍSTICAS DO SETOR TURÍSTICO}

A atividade turística é considerada uma atividade transformadora do espaço por promover o desenvolvimento de diversas localidades permitindo o deslocamento de pessoas, encontros culturais e sociais, bem como a valorização ambiental.

Como atividade econômica e promotora de serviços, o turismo oferece produtos com características de intangibilidade, inseparabilidade (o produto é adquirido e consumido no mesmo instante), heterogeneidade e perecibilidade (o produto não pode ser estocado), o que o configura como um serviço (estas características diferem das dos produtos manufaturados, que permitem outras avaliações quanto à produção e consumo).

Nestes termos, diferentemente do produto físico, o produto turístico baseia-se na experiência vivenciada por seus consumidores, e os consumidores dos produtos turísticos baseiam suas compras na promessa de vivência de determinadas emoções. O processo de tomada de decisão de consumo é complexo, pois envolve decisões de onde ir e o que fazer com avaliações e percepções fundamentadas em um alto risco, uma vez que os mesmos não têm noção exata de como será a viagem até que a mesma seja vivenciada (Smallman \& Moore, 2010).

Em algumas situações, a compra do produto turístico, como por exemplo, o serviço de uma companhia aérea, apresenta o elemento tangível que é o transporte, porém não se sabe se o serviço oferecido por esta empresa estará condizente com o valor pago e a expectativa de um bom serviço vendido. Por esta razão, a maioria dos produtos desta atividade é considerada de alto envolvimento e requer extensivas tomadas de decisões, devido aos elevados custos monetários e não monetários a ela relacionados (Sirakaya \& Woodside, 2005).

Além destas especificidades, as expectativas dos consumidores dos produtos turísticos, em geral, estão motivadas por um conjunto de experiências, visto que o serviço turístico não é controlado por apenas uma companhia, mas envolve, além das atrações e agências de turismo, empresas como restaurantes, complexos de lazer, cassinos, shoppings, companhias áreas, cruzeiros, trens, ônibus, bancos, taxis, casas de câmbio, clínicas médicas, seguros, centro de convenções, jornais, institutos educacionais, agencias de marketing, igrejas 
entre outros (Fleckenstein \& Huebsch, 1999). Este conjunto de empresas envolvidas na prestação do serviço turístico é que o diferencia de outras atividades por exigir diferentes tipos de stakeholders em seus processos.

No âmbito dos negócios, a preocupação empresarial respalda-se nos benefícios gerados para a organização e seus clientes. Porém, na opinião de Walle (1995), para o turismo a preocupação deve ir além destes stakeholders e considerar também outros elementos sociais como, por exemplo, procurar minimizar os impactos causados no encontro entre os turistas e os residentes, gerar o desenvolvimento socioeconômico e inserir os agentes sociais das cidades receptoras desde o planejamento até a prática da atividade turística.

Neste sentido, é necessário compreender que posturas éticas os estudantes dos cursos de turismo apresentam considerando que estes podem se tornar possíveis gestores da atividade turística tomando decisões que irão repercutir sobre a sociedade. Desta forma, o pressuposto ético nas relações de troca faz-se proeminente, visto que, o turismo faz parte de um sistema agregado de marketing, conforme descrito a seguir.

\section{SISTEMA AGREGADO DE MARKETING NA ATIVIDADE TURÍSTICA}

O sistema agregado de marketing é representado por diferentes tipos de sistemas no qual, também, está inserido o turismo. A compreensão de sua essência faz-se necessária para que se possa observar, de forma mais clara, que a atividade turística compõe um sistema com distintas formas de transações. Esse entendimento pode ser visualizado em várias situações de contextos turísticos em que há elementos éticos inseridos.

A atividade de marketing apresenta o pressuposto da troca e em seu sentido mais amplo que a ênfase gerencial remete ao conceito de macromarketing, que inclui considerações da totalidade de qualquer ação de marketing, que transcende a mera venda de produtos entre produtores e clientes (Walle, 1995).

O conceito de macromarketing é colocado por Mascarenhas, Kesavan e Bernacchi (2005) como sendo multidimensional, e que agrega um sistema geral de marketing, onde diversos tipos de relações com os stakeholders ocorrem objetivando o desenvolvimento social. Este sistema de marketing, conforme colocado por Layton (2007), pode ser considerado como uma rede de indivíduos, grupos ou entidades que estão vinculadas direta ou indiretamente, através da participação compartilhada ou sequencial em trocas econômicas que criam, ordenam, transformam, e disponibilizam sortimentos, sejam estes tangíveis ou intangíveis, como resposta as demandas dos clientes. Este sistema geral de marketing apresenta o pressuposto da troca com um amplo conjunto de influências.

Tendo a troca como pressuposto do marketing responsável pela promoção de um conjunto de relações que remetem a um vasto sistema de marketing, pode-se entender que a atividade turística faz parte de um sistema integrado de marketing. Esta consideração está baseada no fato da atividade turística exercer o desígnio da troca em diferentes aspectos. Por exemplo, no caso de um resort, este oferece o serviço de acomodação e os turistas pa- 
gam por sua hospedagem. A sociedade é beneficiada pela criação de empregos, porém serve como suporte para que o empreendimento prospere. Por sua vez, o governo arrecada impostos e ao mesmo tempo oferece concessões a este empreendimento. Como se pode perceber há um conjunto de relações de influências que, de maneira convencional ou não, remetem à troca.

Outro exemplo ilustrativo refere-se aos parques naturais. Nestes ambientes são oferecidos aos turistas o contato com a natureza, a tranquilidade do ambiente, o conhecimento sobre a fauna e a flora etc. Em contrapartida, os turistas, em alguns casos, pagam pelo acesso, cuja renda é revertida na conservação daquele ambiente ou, quando não ocorre tal cobrança, os turistas permitem a absorção de novos conhecimentos e ideias que estão relacionados com uma maior consciência ambiental. Ou seja, neste caso, o parque está proporcionando uma mudança de comportamento.

Assim, a atividade turística pode ser considerada como um grande sistema de marketing que representa um aglomerado de influências que são sentidas entre todas as partes. Em um sentido mais amplo, a atividade turística promove para a sociedade, diversão, infraestrutura, entretenimento, cultura, conhecimento, entre outros elementos. E ao mesmo tempo, recebe apoio e estrutura da sociedade e dos órgãos públicos para que suas atividades sejam desenvolvidas.

Diante de um aglomerado de influências sentidas no sistema de marketing, da atividade turística, dilemas éticos são frequentemente vivenciados por indivíduos que trabalham com tal atividade em que necessitam avaliar suas condutas éticas.

\section{DILEMAS ÉTICOS DA ATIVIDADE TURÍSTICA}

Os indivíduos que trabalham com a atividade turística estão constantemente se deparando com problemas de natureza ética (Weeden, 2002) nos quais têm de tomar decisões que podem prejudicar um determinado grupo de indivíduos. Este é o caso, por exemplo, da construção de equipamentos turísticos em uma determinada localidade que apresenta comunidades indígenas. A instalação destes pode trazer benefícios econômicos para a região através da geração de renda e emprego, entretanto, contribui também para prejuízos relacionados à especulação imobiliária, aumento do custo de vida, depreciação dos costumes locais, entre outros. Neste caso, por se tratar de um local com tradições indígenas, dificilmente esta comunidade não sofrerá nenhuma influência de seus visitantes. Na medida em que, ao frequentarem estas regiões, os turistas estimulam a perda da autenticidade destas comunidades, que passam a exibir em forma de espetáculos, os seus costumes e tradições. Porém, na argumentação contrária, há discussões de que os turistas estimulam a preservação de tais características, pois há a divulgação destas tradições para outras culturas.

A preocupação com os efeitos da atividade turística sobre os recursos naturais e o meio-ambiente também faz parte de outro dilema ético concernente a esta atividade. A presença de um grande número de turistas em áreas naturais, como parques ou reservas, 
ou até mesmo em praias urbanas, contribui para impactos ambientais, segundo Holden (2003), como: a necessidade de drenagens em zona úmidas, destruição de recifes, desflorestamento, poluição e destruição da vegetação natural, entre outros.

Questões éticas são abordadas no artigo de Marnburg (2006), que retrata algumas situações éticas vivenciadas por futuros gestores turísticos em suas atividades profissionais. Entre os dilemas vivenciados pelos mesmos, estão circunstâncias que compõem a construção de um grande resort em área natural, a perseguição sexual, o contrabando de carne que pode prejudicar a saúde dos clientes com sérias infecções, os pequenos furtos, os desfalques ilegais, a prostituição em hotéis, o racismo e a discriminação.

Como se pode verificar, conforme as colocações acima a atividade turística evidencia problemas de natureza ética com difíceis soluções. Muitas destas decisões éticas desencadeiam tensões morais entre as percepções individuais e as exigências do mercado, necessitando de responsabilidades sociais que visem benefícios além da geração de lucro para as empresas. Mas a atividade do marketing vinculada ao setor turístico, sobre o ponto de vista de Wheeler (1995) não apresenta apenas responsabilidades sobre a promoção da zona turística para atrair mais visitantes, mas também sobre a qualidade da experiência que o turista vivencia ao receber também informações de que aquele resort pode não ser indicado a ele. Ou seja, a atividade de marketing objetivando o bem-estar social deve comunicar as realidades e as fragilidades de uma localidade, mostrando ao consumidor uma preocupação baseada no seu real bem-estar.

Tendo em vista os problemas ou dilemas éticos concernentes a atividade turística, faz-se necessário verificar como os futuros profissionais ou gestores da área percebem a presença de tais dilemas no momento de suas ocorrências.

\section{PROCEDIMENTOS METODOLÓGICOS}

Objetivando analisar a percepção ética dos estudantes de graduação diante de dilemas éticos de cunho social, econômico e ambiental comuns a atividade turística utilizou-se como pressuposto o modelo da intensidade moral proposto por Thomas Jones (1991). A percepção de Jones (1991) foi a de que as questões morais variam em termos de sua intensidade moral e de que a proposição de um modelo com as características do tópico moral podem fornecer uma maior compreensão sobre o processo ético que podem ser formalmente validadas e testadas em estudos empíricos.

$\mathrm{Na}$ opinião de Jones, evidências prévias sugeriam que os seres humanos reagem ou respondem de diferentes formas diante de questões morais através de seis características que constituem as questões morais (magnitude das consequências, consenso social, probabilidade de efeito, imediatismo temporal, proximidade e concentração do efeito), que se relacionam positivamente com o comportamento e a tomada de decisão moral. Estas seis características do tópico moral, em conjunto, formam a chamada intensidade moral. As seis características da intensidade moral são apresentadas a seguir: 
- O componente magnitude das consequências é definido como sendo o somatório de malefícios ou benefícios gerados sobre as vítimas ou beneficiários do ato moral em questão. $O$ autor justifica este ponto exemplificando que um ato que causa a morte de seres humanos apresenta uma maior magnitude de consequências do que uma ação que gere sobre uma pessoa um efeito como um ferimento, por exemplo;

- O componente consenso social pode ser entendido como a conformidade social sobre a proposição de um ato ser considerado bom ou ruim. Jones (1991) inclusive argumenta que é difícil uma pessoa agir eticamente se ela não sabe o que a ética prescreve em uma situação, mas o consenso social é uma dimensão que contribui para a redução da ambiguidade existente;

- Outro atributo ou componente da intensidade moral é a probabilidade de efeito da ação moral, que se refere ao grau de probabilidade de uma determinada ação de conteúdo moral relevante ao sujeito venha realmente ocorrer. Para o autor, maior probabilidade de gerar prejuízo, por exemplo, promove um maior cuidado por parte do decisor antes de agir;

- O quarto componente da intensidade moral é o imediatismo temporal, que se refere a quando o efeito da ação poderá ter seus efeitos realizados. Segundo Jones (1991), esta dimensão faz parte da intensidade moral porque as pessoas tendem a minimizar a percepção de intensidade do impacto dos eventos que ocorrerão no futuro, de modo que quanto maior a distância no tempo entre decisão e efeito, maior a disposição do agente de tomar a decisão potencialmente menos ética;

- O quinto componente da intensidade moral é a proximidade, que se refere à proximidade (social, cultural, psicológica ou física) que o agente moral tem dos seus beneficiário ou vítimas da ação em questão. Jones (1991) entende que quanto mais afastadas (socialmente, culturalmente, psicologicamente ou fisicamente) forem às pessoas, menores serão as preocupações com estas no momento do desempenho das decisões éticas.

- O sexto e último componente é a concentração do efeito, que se refere à amplitude do impacto sobre as pessoas, e é uma função inversa ao número de indivíduos afetados pela ação de uma dada magnitude. Ou seja, para o autor, se o efeito de uma decisão é concentrado uma pessoa, a avaliação é diferentes do que a situação em que o efeito recairia sobre muitas pessoas.

Assim, sobre a perspectiva das seis características do tópico moral propostas por Jones (1991) foi desenvolvida uma escala. Para a contextualização dos dilemas éticos fez-se uso da construção de cenários que permite que o entrevistado esteja diante de uma situação de contexto ético em que tem de tomar um posicionamento. Wason, Polonsky e Hyman (2002), evidenciam que os cenários devem conter variáveis chaves, representarem situações reais, serem claros e imparciais. Seguindo tais recomendações relativas à construção de cenários foram desenvolvidos três cenários, abordando circunstâncias éticas em nível social, 
econômico e ambiental conforme apresentado abaixo.

Figura 1 - Cenários desenvolvidos

\begin{abstract}
Cenário 1:
Uma famosa empresa turística há vários anos apresenta como principal destino turístico passeios a uma pequena comunidade litorânea, que além de propiciar o contato com a natureza, permite momentos de tranquilidade a seus visitantes. Esta empresa é muito bem quista pelos moradores desta comunidade por proporcionar a estes a geração de renda tão necessária para o seu desenvolvimento. Este sentimento amigável é que tem incentivado esta empresa a intensificar o envio de turistas a esta região. 0 que esta comunidade e empresa turística não esperavam era o acontecimento de uma tragédia natural que destruiu uma parte desta localidade. Diante desta situação, a empresa turística percebeu que devido às circunstâncias deveria reduzir os passeios turísticos a esta localidade durante o restabelecimento da mesma e que esta decisão só iria afetar uma parte desta comunidade, pois a outra parte continuaria servindo de estrutura para os turistas. Em contrapartida, a comunidade considera esta atitude errada e egoísta e que esta decisão poderá causar desemprego para muitas famílias que dependem do turismo e que neste momento precisam destes visitantes para reerguer a parte afetada.
\end{abstract}

Ação: A empresa turística decidiu reduzir o envio de turistas a esta comunidade enquanto a mesma não seja restabelecida

\title{
Cenário 2:
}

Um agente de turismo acaba de ser contratado por uma agência de viagens para operar na venda de passagens aéreas. Este operador coincidentemente, no seu primeiro dia de emprego, obteve a oportunidade de fazer negócio a partir da indicação de um amigo, que recomendou a venda de passagens para seus pais e seus tios (04 pessoas) que iriam sair de férias para o Caribe ainda em dez meses. Entretanto, este mesmo agente, há poucos minutos antes de saber da realização deste negócio, havia recebido de seu chefe um comunicado sobre uma promoção de passagens aéreas que teria início no dia seguinte para este mesmo destino. $O$ agente de turismo já presenciou, por parte de outros agentes, finalizações de negócios em situações parecidas e entende que a conclusão deste negócio resultará em uma boa visibilidade por parte de seus superiores. Até porque tal atitude só irá prejudicar financeiramente poucas pessoas.

Ação: O agente de turismo concluiu o negócio.

\section{Cenário 3:}

O proprietário de conhecido resort recebeu incentivos fiscais para montar uma filial em uma pequena cidade com reserva de mata atlântica. Os governantes desta localidade perceberam no turismo uma importante fonte de renda que contribuiria para a geração de emprego, lazer e investimentos em infraestrutura, pois o resort se comprometeu em gerar benefícios para a área em seu entorno. O proprietário do resort ficou interessado em construir tal empreendimento em uma região que ele desconhecia. O único problema para a instalação deste empreendimento está na área em que este será construído, visto que a única extensão de terra propícia para o seu estabelecimento é a área da reserva de mata atlântica. 0 empresário diante deste contexto propôs construir o resort sem prejudicar a mata. Todavia, os moradores da cidade e organizações de preservação ambiental alegam que mesmo que o empreendimento se comprometa a preservar a mata ela sofrerá algum tipo de dano, mesmo sendo ele pequeno e não imediato, pois a fauna e a flora acabam sentindo ao longo dos anos o efeito da presença dos visitantes, bem como das instalações. Além disso, argumenta-se que a presença do resort, nesta área de reserva, irá prejudicar a ventilação da população próxima a ele.

O empresário do empreendimento, bem como os governantes da cidade estão cientes da necessidade ambiental de preservar tal reserva, porém percebem que os benefícios gerados a esta cidade são superiores a probabilidade da ocorrência de tais efeitos negativos alegados pelos moradores e ambientalistas.

Ação: O empresário resolve construir o resort na área da reserva com o consentimento dos governantes da cidade.

Fonte: Elaboração própria 
Para cada um dos cenários desenvolvidos o estudante teve de se posicionar em relação, aos itens relacionados às seis características da intensidade moral. Cada um destes itens, da escala, foi aferido através da escala phrase completion proposta por Hodge e Gillspie (2007). Nesta escala os itens expedem uma intensidade, ou seja, na verdade, os itens são complementados pela sua indicação de intensidade em uma escala de 11 pontos que variam de 0 a 10.

Para compor o grupo de estudo foram selecionados 103 estudantes graduandos do curso de turismo de uma universidade pública do nordeste brasileiro considerando uma amostragem não probabilística por acessibilidade e conveniência.

Figura 2 -Itens da intensidade moral para a atividade turística

\section{Magnitude das consequências}

Para mim, o malefício final resultante da ação (da empresa turística / do agente de turismo / do empresário do resort) será

Pouco significativo Razoavelmente significativo Muito significativo

\begin{tabular}{|l|l|l|l|l|l|l|l|l|l|l|}
0 & 1 & 2 & 3 & 4 & 5 & 6 & 7 & 8 & 9 & 10 \\
\hline
\end{tabular}

\section{Consenso social}

Acredito que existe um consenso, por parte da sociedade, de que a ação (da empresa turística / do agente de turismo / do empresário do resort) seja

Pouco correta
\begin{tabular}{|l|l|l|l|l|l|l|l|l|l|l|} 
Razoavelmente correta & \multicolumn{8}{c}{ Muito correta } \\
0 & 1 & 2 & 3 & 4 & 5 & 6 & 7 & 8 & 9 & 10 \\
\hline
\end{tabular}

\section{Probabilidade de efeito}

Acredito que a probabilidade de se gerar um malefício pela ação (da empresa turística / do agente de turismo / do empresário do resort) seja

Pouco significativa Razoavelmente significativa Muito significativa

\begin{tabular}{|l|l|l|l|l|l|l|l|l|l|l|}
0 & 1 & 2 & 3 & 4 & 5 & 6 & 7 & 8 & 9 & 10 \\
\hline
\end{tabular}

\section{Imediatismo temporal}

Para mim, o dano imediato provocado pela ação (da empresa turística / do agente de turismo / do empresário do resort) será

Insignificante Razoavelmente significativo Muito significativo

\begin{tabular}{|l|l|l|l|l|l|l|l|l|l|l|}
0 & 1 & 2 & 3 & 4 & 5 & 6 & 7 & 8 & 9 & 10 \\
\hline
\end{tabular}

\section{Proximidade}

Para mim, o efeito danoso (se houver) proveniente da ação (da empresa turística / do agente de turismo / do empresário do resort) irá afetar pessoas que são

Pouco próximas a ela Razoavelmente próximas a ela Muito próximas a ela

\begin{tabular}{|l|l|l|l|l|l|l|l|l|l|l|}
0 & 1 & 2 & 3 & 4 & 5 & 6 & 7 & 8 & 9 & 10 \\
\hline
\end{tabular}

\section{Concentração do efeito}

Acredito que os prejuízos causados pela ação (da empresa turística / do agente de turismo / do empresário do resort) irão prejudicar

Poucas pessoas Um razoável no de pessoas

\begin{tabular}{|l|l|l|l|l|l|l|l|l|}
0 & 1 & 2 & 3 & 4 & 5 & 6 & 7 & 8 \\
\hline
\end{tabular}

Fonte: Elaboração própria 


\section{ANÁLISE E DISCUSSÃO DOS RESULTADOS}

Analisando os resultados da pesquisa realizada com 103 estudantes graduandos do curso de turismo de uma universidade pública do nordeste brasileiro observou-se que a amostra não indicou a existência de missing values e outliers (este último aspecto foi verificado através da análise de frequência dos valores das variáveis padronizadas em Z).

Quadro 1 - Características dos graduandos do curso de turismo

\begin{tabular}{|c|c|c|c|c|c|c|}
\hline \multicolumn{3}{|c|}{ Ano letivo } & \multicolumn{4}{|c|}{ Atividade } \\
\hline Ano & Frequência $\mathbf{P}$ & Percentual & Condição & \multicolumn{2}{|c|}{ Frequência } & Percentual \\
\hline Primeiro & 33 & 32,1 & Não está trabalhando & \multicolumn{2}{|c|}{52} & 50,5 \\
\hline Segundo & 19 & 18,5 & Está trabalhando em meio turno & \multicolumn{2}{|c|}{38} & 36,9 \\
\hline Terceiro & 22 & 21,4 & Está trabalhando integralmente & \multicolumn{2}{|c|}{13} & 12,6 \\
\hline Quarto & 20 & 19,4 & & & & \\
\hline Quinto & 09 & 8,7 & & & & \\
\hline \multicolumn{3}{|c|}{ Gênero } & \multicolumn{4}{|c|}{ Estado civil } \\
\hline Opções & N. & $\%$ & Opções & N. & $\%$ & \\
\hline Feminino & 69 & 67,0 & Solteiro & 101 & 98,1 & \\
\hline \multirow[t]{2}{*}{ Masculino } & 34 & 33,0 & Casado & 2 & 1,9 & \\
\hline & & & Viúvo & 0 & 0 & \\
\hline \multicolumn{3}{|c|}{ Idade } & \multicolumn{4}{|l|}{ Renda } \\
\hline Faixas & N. & $\%$ & Faixas & & $\mathbf{N}$. & $\%$ \\
\hline Até 20 anos & 32 & 31,1 & Até $\mathrm{R} \$ 1.000,00$ & & 17 & 16,5 \\
\hline De 20 até 21 anos & 26 & 25,2 & Acima de $R \$ 1.000,00$ até $R \$ 2.00$ & 0,00 & 30 & 29,1 \\
\hline De 22 até 24 anos & 32 & 31,1 & Acima de $R \$ 2.000,00$ até $R \$ 3.00$ & 00,00 & 23 & 22,3 \\
\hline Acima de 24 anos & 13 & 12,6 & Acima de $R \$ 3.000,00$ & & 33 & 32,0 \\
\hline
\end{tabular}

Fonte: Dados da pesquisa

Em meio às características dos estudantes, que estão mostradas no Quadro 1, está a presença do maior número de respondentes no primeiro ano de curso, acompanhado do terceiro ano letivo. Esta ocorrência, provavelmente, deve estar relacionada à blocagem dos alunos que no primeiro ano cursam todas as disciplinas do primeiro e segundo períodos e no decorrer do curso, por começarem a trabalhar na área ou a realizarem estágios, passam a não cursar todas as disciplinas requeridas no período.

Com relação às outras características desta amostra, verificou-se que 50,5\% da mesma não está exercendo nenhuma atividade profissional. Esta é, em sua maior parte, do sexo feminino $(67,0 \%)$, solteiros $(98,1 \%)$, com faixa etária até 20 anos e entre 22 e 24 anos e renda familiar superior de $\mathrm{R} \$ 3.000,00$ (32,0\%). Estas são características comuns aos estudantes de graduação, que em geral, são jovens, solteiros e estão em processo de aprendizagem para exercerem uma atividade profissional.

Também foram verificadas as medidas descritivas (média, desvio padrão, assimetria e curtose) de cada uma das variáveis. Ou seja, para todas as variáveis quanto maior o escore anotado, maior será a intensidade percebida. Entretanto, para as variáveis "consenso social" e "proximidade", quanto maior o escore anotado, maior é a predisposição do indivíduo de 
agir de forma antiética. Em relação ao desvio padrão, os valores até 2 indicam baixa dispersão, de 2 a 3 dispersão moderada e acima de 3 elevada dispersão. Já para a assimetria e curtose foram utilizados os critérios do SPSS, de que valores entre -1 e +1 indicam normalidade da variável, e valores fora deste intervalo indicam não normalidade.

Tendo em vista os resultados para o primeiro cenário foi possível averiguar que as médias estiveram, em sua maioria, acima do ponto intermediário 5 da escala, com destaque para as variáveis "magnitude das consequências" $(6,78)$ e para a "concentração do efeito" $(6,64)$, que apresentaram medidas próximas do ponto 7 da escala. Para as variáveis "Consenso social" e "Proximidade" observa-se uma predisposição de ações mais antiéticas. Ou seja, a maioria dos estudantes acreditam que existe um consenso, por parte da sociedade, de que a ação da empresa turística foi razoavelmente correta e que tal ação iria prejudicar pessoas próximas a elas.

Ou seja, no entendimento dos entrevistados há um cuidado em não prejudicar as pessoas que estão próximas a elas, independente da ação ser considerada como antiética. Para os desvios padrões, nota-se uma maior dispersão para a variável "proximidade", tendo como resultado 2,75. Esta dispersão da variável "Proximidade" corrobora como a sua alta média.

Tabela 1 - Medidas do cenário 1

\begin{tabular}{lcccc}
\hline \multicolumn{1}{c}{ Variável } & Média & Desvio padrão & Assimetria & Curtose \\
\hline Magnitude das conse- & 6,78 & 1,97 & $-0,41$ & $-0,55$ \\
quências & 5,38 & 2,53 & $-0,16$ & $-0,73$ \\
Consenso social & 6,08 & 2,27 & $-0,54$ & $-0,22$ \\
Probabilidade de efeito & 6,41 & 2,22 & $-0,48$ & $-0,30$ \\
Imediatismo temporal & 6,16 & 2,75 & $-0,68$ & $-0,41$ \\
Proximidade & 6,64 & 2,00 & $-0,26$ & $-0,24$ \\
Concentração do efeito &
\end{tabular}

Fonte: Dados da pesquisa

Ao analisar as medidas ou coeficientes da assimetria e curtose, a grande maioria das variáveis se estabeleceu dentro da normalidade (medidas entre -1 e +1 ) entendendo-se que todas as variáveis estão dentro da normalidade, neste primeiro cenário.

Para o cenário de dilema econômico, observa-se que as médias estão mais próximas do ponto 5 da escala. Médias baixas ficaram para as variáveis "consenso social" $(3,99)$ e "concentração do efeito" $(3,67)$. Para a variável "consenso social" verifica-se, neste cenário, uma percepção mais ética e para a concentração do efeito uma postura mais antiética.

O que se percebe é que, pelo fato, da ação não prejudicar muitas pessoas, os pesquisados acreditam que a ação não se caracterizaria como antiética como foi observado no cenário anterior, em que as consequências da ação repercutiram sob um número maior de indivíduos. Já para "consenso social", houve uma tendência de uma postura mais ética em comparação com o cenário anterior.

Apesar da variável "proximidade" ter apresentado uma menor média em relação ao cenário de dilema social, esta ainda se destaca como uma postura pouco ética, demostran- 
do que os estudantes pesquisados, de certa forma, agem de forma mais ética com pessoas conhecidas do que com as desconhecidas. Todavia, independente da relação de proximidade com o receptor da ação, posturas éticas deveriam ocorrer.

Os desvios-padrões estiveram em um nível moderado de dispersão. Em geral, considera-se uma propensão para uma ação pouco ética por parte do agente de viagem e a crença da existência de um grande dilema ético. Estas dispersões indicam que os respondentes apresentam maiores divergências de opiniões.

Tabela 2 - Medidas do cenário 2

\begin{tabular}{lcccc}
\hline \multicolumn{1}{c}{ Variável } & Média & Desvio padrão & Assimetria & Curtose \\
\hline Magnitude das conse- & 5,64 & 2,15 & $-0,36$ & 0,00 \\
quências & & 2,56 & 0,39 & $-0,55$ \\
Consenso social & 3,99 & 2,21 & $-0,31$ & $-0,43$ \\
Probabilidade de efeito & 5,65 & 2,49 & $-0,29$ & $-0,67$ \\
Imediatismo temporal & 5,30 & 2,87 & $-0,11$ & $-1,15$ \\
Proximidade & 5,28 & 2,29 & 0,77 & 0,06 \\
Concentração do efeito & 3,67 & & & \\
\hline
\end{tabular}

Fonte: Dados da pesquisa

Os resultados da assimetria e curtose denotam que a maioria das variáveis esteve dentro do parâmetro da normalidade. Indicação de não normalidade relacionou-se a curtose para a variável "proximidade". Estatisticamente, o cenário de dilema econômico, em geral, apresentou indícios de percepções éticas diferentes entre os respondentes em comparação com o cenário de dilema social.

No terceiro cenário de dilema ambiental, os valores das médias para a "proximidade" foram menores e da "concentração do efeito" maiores. Entretanto, as médias da variável "proximidade" e da "concentração do efeito" foram diferentes das médias do segundo cenário.

De maneira geral, infere-se que houve um posicionamento de forma mais ética neste cenário. Esta constatação pôde ser averiguada ao analisar as suas médias para as variáveis "magnitude das consequências", "probabilidade de efeito", "imediatismo temporal" e "concentração do efeito" que foram próximas ao ponto 6 da escala ou acima dele. Menores médias ficaram para o "consenso social" $(3,13)$ e a "proximidade" $(3,50)$ que apresentam suas magnitudes invertidas, ambas indicando um posicionamento mais ético neste cenário.

Os resultados para o cenário de dilema ambiental demostra um resultado que condiz com os debates e discussões que vêm ocorrendo, nos cursos de graduação em turismo, nos últimos anos, sobre melhores práticas ambientais e de sustentabilidade. Tais discussões e debates podem ter repercutido para uma postura mais ética diante de tal dilema, uma vez que muitos cursos de graduação em turismo apresentam disciplinas específicas que tratam de aspectos ambientais. No caso dos estudantes pesquisados a sua grade curricular abrange disciplinas que abordam a relação da atividade turística com o meio ambiente e seus aspectos éticos.

Ao observar o desvio-padrão das variáveis alta dispersão pode ser averiguada em re- 
lação à "proximidade" $(3,27)$ apresentando divergência de respostas em relação a este item. Ao analisar esta variável nota-se que nos três cenários a mesma apresentou, em todas as situações, maiores dispersões em relação às outras variáveis em análise. Isso significa inferir que os estudantes apresentam dificuldade em possuir posturas éticas quando o efeito da ação poderá recair sobre alguém que o mesmo conhece.

Tabela 3 - Medidas do cenário 3

\begin{tabular}{lcccc}
\hline \multicolumn{1}{c}{ Variável } & Média & Desvio padrão & Assimetria & Curtose \\
\hline Magnitude das conse- & 7,50 & 2,11 & $-1,01$ & 0,33 \\
quências & 3,13 & 2,29 & 0,45 & $-0,81$ \\
Consenso social & 7,19 & 2,14 & $-0,79$ & 0,23 \\
Probabilidade de efeito & 6,34 & 2,41 & $-0,46$ & $-0,54$ \\
Imediatismo temporal & 3,50 & 3,27 & 0,59 & $-1,09$ \\
Proximidade & 7,36 & 2,20 & $-0,82$ & 0,01 \\
Concentração do efeito & 7,36
\end{tabular}

Fonte: Dados da pesquisa

Ao avaliar os coeficientes de assimetria e curtose, a grande parte das variáveis está dentro da normalidade, com medidas entre -1 e +1 . A exceção ficou relacionada à medida de assimetria da variável "consenso social". Esta variável apresentara coeficiente um pouco acima de -1, que não impede de considerá-las normais.

Já na análise de correlação entre as seis variáveis da intensidade moral proposta por Jones (1991) foi possível observar que a variável "consenso social" se relacionou positivamente nos cenários de dilema econômico e ambiental com a variável "magnitude das consequências". Correlações nulas ocorreram entre as variáveis "magnitude das consequências" e a "proximidade" para os três cenários. Nulidades também aconteceram entre "proximidade" e as variáveis "Consenso social" e "Probabilidade do efeito" nos três cenários. Tais dados indicam que questões relativas à "proximidade" não se relacionam com outros preceitos éticos. Ou seja, a variável "proximidade" do pondo de vista ético necessita ser avaliada em separado, pois não se relaciona com os demais componentes dos preceitos éticos elencados pela teoria de Tomas Jones (1991). Todavia, correlações significativas entre a "proximidade" puderam ser averiguadas para o cenário de dilema econômico para as variáveis "imediatismo temporal" e "concentração do efeito".

Desta forma, é possível averiguar, na análise de correlação, que o cenário de dilema econômico apresentou as maiores correlações entre as variáveis em estudo inferindo a necessidade de maiores análises éticas sobre ele. 
Tabela 4 - Correlação para os três cenários

\begin{tabular}{ccccccc}
\hline Dim. & Cenário & Mag. & Cons. & Prob. & Imed. & Proxi. \\
\hline \multirow{2}{*}{ Cons. } & Cenário 1 & $-0,048^{*}$ & & & & \\
& Cenário 2 & $-0,451$ & & & & \\
& Cenário 3 & $-0,389$ & & & & \\
Prob. & Cenário 1 & 0,565 & $-0,146^{*}$ & & & \\
& Cenário 2 & 0,701 & $-0,497$ & & & \\
& Cenário 3 & 0,651 & $-0,284$ & & & \\
Imed. & Cenário 1 & 0,480 & $-0,139^{*}$ & 0,525 & & \\
& Cenário 2 & 0,670 & $-0,377$ & 0,695 & & \\
& Cenário 3 & 0,511 & $-0,263$ & 0,527 & & \\
Proxi. & Cenário 1 & $-0,088^{*}$ & $0,154^{*}$ & $0,067^{*}$ & $0,026^{*}$ & \\
& Cenário 2 & $0,183^{*}$ & $-0,106^{*}$ & $0,161^{*}$ & 0,233 & \\
& Cenário 3 & $0,032^{*}$ & $0,191^{*}$ & $-0,095^{*}$ & $-0,027^{*}$ & \\
& Cenário 1 & 0,423 & $-0,185^{*}$ & 0,437 & 0,468 & $0,072^{*}$ \\
Conc. & Cenário 2 & 0,345 & $-0,223$ & 0,449 & 0,482 & 0,279 \\
& Cenário 3 & 0,583 & $-0,389$ & 0,595 & 0,457 & $-0,073^{*}$
\end{tabular}

Obs. Os valores apresentados em asterisco denotam valores que apresentam correlação estatisticamente nula.

Legenda: Mag - Magnitude das consequências, Cons - Consenso social, Prob -

Probabilidade de efeito, Imed - Imediatismo temporal, Proxi - Proximidade, Conc - Concentração do efeito.

Fonte: Dados da pesquisa

\section{CONSIDERAÇÕES FINAIS}

A atividade turística, assim, como outras áreas que possuem efeitos sociais apresenta situações de dilemas éticos, no qual os indivíduos necessitam se posicionar gerando ações que podem beneficiar ou não outras pessoas. Como futuros tomadores de decisões ou prestadores de serviços os estudantes que cursam o curso de Bacharelado em turismo em diversas universidades devem apresentar posturas éticas, visto que serão agentes sociais no futuro realizando atividades que afetarão direta ou indiretamente a atividade turística e a sociedade em que vivem.

Assim, um estudo sobre tais posturas éticas com um grupo de 103 estudantes foi desenvolvido e os resultados das medidas para o cenário 3 (dilema ecológico), indicaram maiores posturas éticas por parte dos estudantes, apesar do desvio padrão ter dado alto para a variável "proximidade". Dificuldade de um posicionamento mais ético ficou por parte do dilema de cunho econômico, em que a maioria das médias ficou próxima do ponto intermediário da escala. O que ocorre é que independente do dilema do cenário, posturas éticas devem ocorrer por parte destes futuros agentes sociais. Provavelmente as atuais discussões sobre as questões ambientais em nível mundial tenham influenciado uma postura mais ética diante deste cenário. Além de alguns cursos de graduação apresentam em suas estruturas curriculares disciplinas específicas que abordem a ética e o meio ambiente, como é o caso. Entretanto, uma tendência a um posicionamento mais antiético pôde ser percebido no dilema econômico, permitindo uma interpretação de que as questões financeiras podem in- 
fluenciar tais indivíduos a agirem de forma antiética no futuro.

Considerando a análise de correlação o destaque ficou para as correlações estatisticamente nulas em relação a variável "proximidade". Este resultado denota que questões relacionadas à proximidade do agente social necessitam ser analisadas em separado das demais variáveis de cunho ético, visto que foram poucas as situações em que esta variável se relacionou positivamente com outro preceito ético.

Destarte, foi possível observar, com tal estudo, que uma atenção maior deve ser dada, por parte das universidades e dos cursos técnicos na área de turismo, para estes estudantes. Preceitos e análises éticas necessitam serem estimuladas e discutidas em tais ambientes para que a sua formação profissionais ocorra da melhor forma possível promovendo e desenvolvendo agentes sociais conscientes e íntegros.

Destaca-se, ainda, que o presente trabalho considerou um específico curso de graduação em turismo, e que tais resultados podem variar com o tempo, com a estrutura curricular e com o tipo de instituição. Desta forma, futuras pesquisas sobre esta temática em outras instituições e localidades faz-se proeminente. Além disso, outros cenários podem ser desenvolvidos considerando diferentes dilemas éticos que fazem parte da atividade turística, devendo estes serem validados estatisticamente.

\section{REFERÊNCIAS}

Fleckensteing. Marilynn; Huebsch, Patricia (1999). Ethics in tourism-reality or hallucination. Journal of Business Ethics, n. 19, pp. 137-142.

Hodge, D. R., \& Gillespie, D.F. (2007). Phase completion scales: a better measurement approach than likert scales? Journal of Social Service Research, 33 (4): $1-12$.

Holden, A. (2003).In need of new environmental ethics for tourism? Annals of Tourism Research, 30 (1): $94-108$.

Jones, T. M. (1991). Ethical decision making by individuals in organizations: an issue-contingent model. Academy of Managementt Review, 16 (2): 366-395.

Layton, R. (2007). Marketing systems: a core macromarketing concept. Journal of Macromarketing, $27,227-242$.

Marnburg, E. (2006). I hope it won't happen to me! Hospitality and tourism students' fear of difficult moral situations as managers. Tourism Management, 27, 561 - 575.

Mascarenhas, O. A. J., Kesvan, R., \& Bernacchi, M. D. (2005). Governmental and corporate role in diffusing development technologies: Ethical macromarketing imperatives. Journal of Nonprofit and Public Sector Marketing, 13 (1): $271-291$.

Sirakaya, E., \& Woodside, A. G. (2005). Building and testing theories of decision making by travellers. Tourism Management, 26, $815-832$. 
Smallman, C., \& Moore, K. (2010). Process studies of tourists' decision-making. Annals of Tourism Research, 37 (2): $397-422$.

Walle, A. H. (1995). Business ethics and tourism: From micro to macro perspectives. Tourism Management, 16 (4): $263-268$.

Wason, K. D., Polonshy, M. J., \& Hyman, M. R. (2002). Designing vignette studies in marketing. Australasian Marketing Journal, 10 (3): $41-87$.

Weeden, C. (2002). Ethical tourism: an opportunity for competitive advantage? Journal of Vacation Marketing, 8 (2): $141-153$.

Artigo recebido em: 07/03/2015.

Artigo aprovado em: 13/04/2016. 